\title{
1204 Estimating Fatigue Crack Initiation of Aluminum Die Cast Alloy using Image Based Finite Element Analysis
}

Sujit BIDHAR, Graduate School of Engineering, The University of Tokyo, Hongo, Bunkyo-ku, Tokyo.
Nobuhiro YOSHIKAWA, Institute of Industrial Science, The University of Tokyo. Komaba, Meguro, Tokyo

Key Words: X-ray CT, Fatigue, Finite Element, Die Cast, Gas Pore, Aluminum Alloy

Abstract: In this study X-ray CT image is used for meso-scale surface modeling of irregular shaped gas pores in aluminum die cast alloy, followed by image based finite element analysis to evaluate crack initiation point. There is a good agreement between the location of maximum principal stress found by the analysis and location of crack initiation on actual fractured surface. We conclude that meso-scale image based finite element method is promising for fatigue life prediction of aluminum die cast alloy.

\section{INTRODUCTION}

Many automobile parts are made by high pressure die casting process of aluminum alloys. Such process induces micro pores in the die cast parts. Many studies have shown that porosity has the most critical influence on fatigue strength of $\mathrm{Al}-\mathrm{Si}$ casting alloys where it acts as preferential site for fatigue-crack initiation [1]. However, the fatigue crack seems to initiate from certain pores at random. We have investigated an application of X-ray CT to visualize and track the fatigue crack so as to figure out fatigue mechanism initiated by pores [2]. In this study, an attempt is made to predict the location of fatigue crack initiation by using image based finite element analysis in meso-scale. Three dimensional surface model of gas pores was constructed using X-ray CT images and used in finite element model to get principal stress distribution. There is a good agreement between the location of the maximum principal stress and the crack initiation site found by actual fracto-graphy after fatigue test. So the meso-scale image based finite element analysis can be used as a predictive tool for crack initiation.

\section{METHODOLOGY}

A region of high stress concentration is created around certain gas pores which reduce the time for fatigue-crack initiation [3]. It is thought that large pores act as notches to concentrate stress on smaller pores which leads to crack initiation. So it is targeted to get the location of the maximum principal stress by finite element analysis of entire specimen. Figure 1 shows the dimensions of round bar aluminum die cast fatigue test piece along with $\mathrm{X}$-ray $\mathrm{CT}$ scanned region. VOXELCON software is used to reconstruct three- dimensional surface model of irregular shaped gas pores, from the $\mathrm{X}$-ray CT images of aluminum die cast fatigue test specimen.

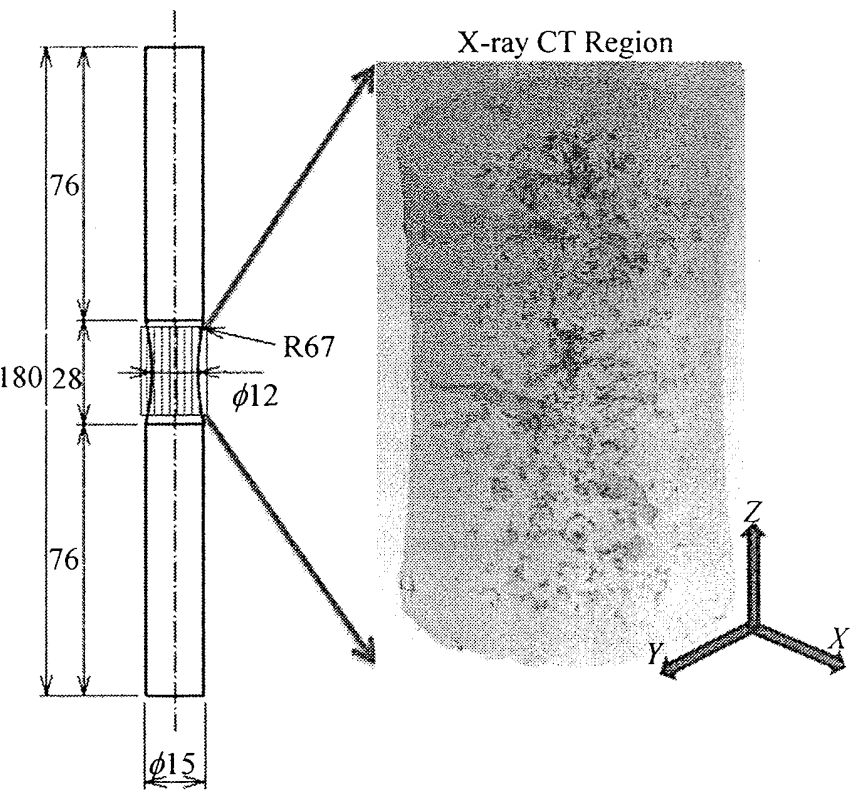

Fig. 1 Round bar aluminum die cast test piece

This model is used in finite element analysis for static elastic stress in three-dimension for entire specimen. For finite element modeling, 10-node tetrahedral elements are used with minimum size of $300 \mu \mathrm{m}$ in order to limit the number of elements within the solver capability. Mesh is optimized in order to get finer elements around irregular shaped gas pores having higher curvatures and relatively bigger elements are created where there is no material discontinuity. Total number of elements and nodes are 198,922 and 251.520 , respectively. The bottom plane of the test piece is fixed and uniform tensile stress of $10 \mathrm{MPa}$ is applied to the top plane. Young's modulus of $76 \mathrm{GPa}$ and Poisson's ratio of 0.3 are used as 
material properties. To compare the predicted result of finite element analysis, fatigue test is also carried out on the same test piece with stress amplitude of $80 \mathrm{MPa}$ until fracture, and the location of fracture plane and the fracture causing gas pores are identified from fracto-graphy of fractured surface.

\section{RESULTS AND DISCUSSION}

Figure 2 shows the principal stress distribution for the test piece exposing the cross sectional plane containing the maximum principal stress along with un-deformed model in shade. The maximum principal stress is found to be $39.97 \mathrm{MPa}$. So there is a stress concentration factor of 3.997 near the gas pore. Figure 3(a) shows the detailed principal stress distribution around the gas pore in the cross sectional plane containing the maximum stress value. Figure $3(\mathrm{~b})$ shows the fractography of the crack origin. The finite element analysis shows the location of maximum stress to be at $6.84 \mathrm{~cm}$ from the bottom portion. The broken fatigue test specimen shows the broken portion is somewhere between $5 \mathrm{~cm}$ to $7.6 \mathrm{~cm}$

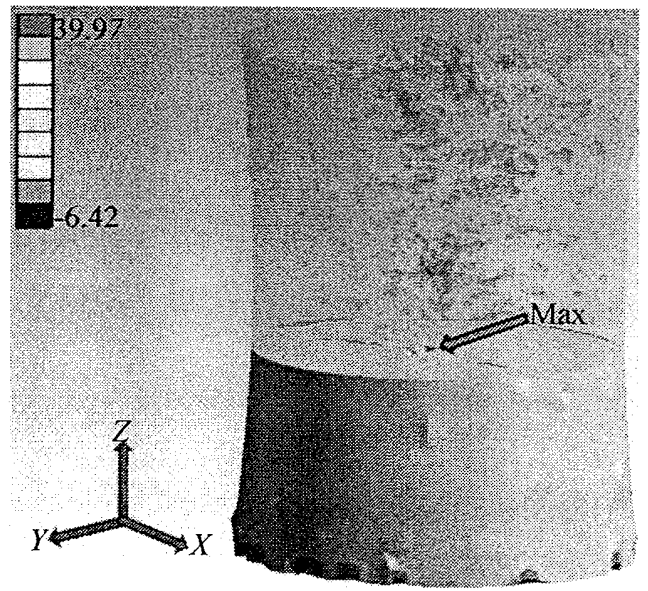

Fig. 2 Maximum principal stress distribution obtained by image based finite element analysis

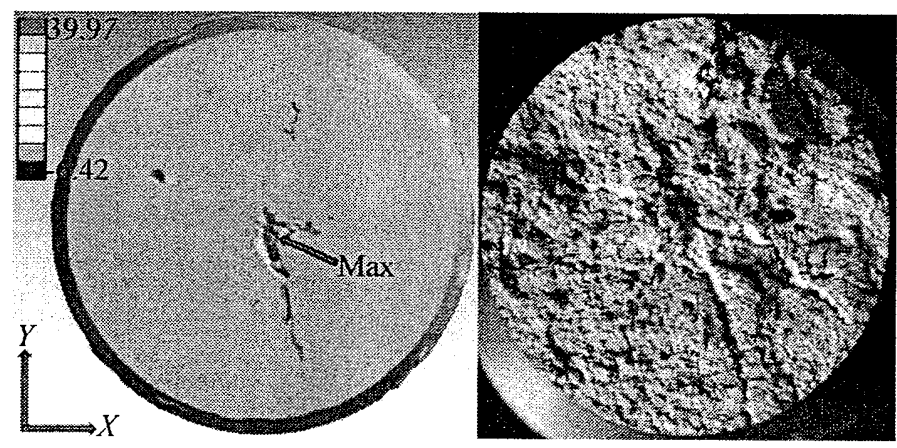

(a) Maximum principal stress distribution in fractured plane

(b) Actual fractured surface

Fig. 3 Comparison between finite element analysis and fracto-graphy from the bottom. X-ray CT images of broken test piece is also used to reconstruct three-dimensional surface model, and is compared with surface model of the same test piece before fatigue test, in order to identify which gas pore has resulted in crack initiation. Comparing Fig. 3(a) and (b) confirms that the same pore, around which there is the maximum stress concentration, has resulted in crack. Thus, the proposed methodology to evaluate the maximum principal stress can be used as an indicator for predicting fatigue crack initiation. Various pore parameters such as pore size, spacing, orientation to loading direction, aspect ratio seem to influence the maximum principal stress and its location. A systematic study of these factors is also conducted and will be published in future. It must be noted that this particular specimen contains bigger size pores, so that a fairly coarse mesh in finite element model is sufficient to resolve the stresses around pore geometry. If many small size pores are present, then a finer mesh will be needed to evaluate maximum principal stress correctly, as stress values are quite sensitive to mesh size.

\section{CONCLUSIONS}

The maximum principal stress as a prediction tool for fatigue crack initiation in aluminum die cast alloy is proposed. Meso-scale image based finite element analysis can be used as a non destructive method to evaluate possible fatigue crack initiation site. It is shown that the gas pore, around which the principal stress is maximized, has resulted in fatigue crack. Detailed investigation is required in order to understand the effect of gas pore interactions on the maximum principal stress.

\section{References}

1. Sonsino, C. M., "Fatigue strength and application of cast aluminum alloys with different degrees of porosity", International Journal of Fatigue, Vol.15(2), 1993, pp.75-84.

2. Kuwazuru, O. et al., "X-ray CT inspection for porosities and its effect on fatigue of die cast aluminum alloy", Journal of Solid Mechanics and Materials Engineering, Vol.2(9), 2008, pp.1220-1231.

3. Marrow, T. J., "High resolution X-ray tomography of short fatigue crack nucleation in austempered ductile cast iron", International Journal of Fatigue, Vol.26(7), 2004, pp.717-725. 